\title{
A distributed model for real-time flood forecasting using digital elevation models
}

\author{
Luis Garrote, Rafael L. Bras* \\ Ralph M. Parsons Laboratory, Department of Civil and Environmental Engineering, Room 1-290, \\ Massachusetts Institute of Technology, Cambridge, MA 02139, USA
}

Received 28 May 1993; revision accepted 25 July 1994

\begin{abstract}
A distributed model for real-time rainfall-runoff simulation during floods is presented. The model, called Distributed Basin Simulator (DBSIM) is based on the detailed topographical information provided by Digital Elevation Models (DEM). Basin representation uses the rectangular grid of the DEM. Soil properties, input data and state variables are also represented as data layers using the same scheme. Distributed rainfall input is used to map the topographically driven evolution of saturated areas as the storm progresses. The model applies a kinematic model of infiltration to evaluate local runoff generation in grid elements and accounts for lateral moisture flow between elements and surface flow routing in a simplified manner. Model performance is evaluated through sensitivity analyses and an exercise of model calibration and verification.
\end{abstract}

\section{Introduction}

Despite the abundance of modeling schemes, flood forecasting still remains one of the unsolved problems of operational hydrology. The gaps between data availability and modeling strategy are still apparent in many practical applications (Duckstein et al., 1985). On one hand, many successful schemes are based on stochastic approaches which usually neglect available information about physical characteristics of river basins. On the other hand, deterministic modeling of hydrologic response in midsize basins still evades the efforts of applied hydrologists. Knowledge about basin morphology is difficult to include in operational schemes without multiplying the need for additional physical information, generally at a great cost.

\footnotetext{
* Corresponding author.
} 
New approaches to the problem of deterministic simulation of basin response can benefit greatly from two recent developments in data availability: (1) detailed topographical descriptions of river basins at low cost, in the form of Digital Elevation Models (DEM), and (2) instantaneous measurement of the spatial development of precipitation, in the form of radar-generated rainfall maps. Both represent a qualitative change with respect to the type of information previously available, which can not be neglected in new modeling efforts. The objective of the research presented here was to develop a model that could use intensively the topographical information provided by the DEM coupled with distributed rainfall in a floodforecasting context.

Distributed modeling is the only viable option to incorporate this new information into the modeling process. However, although the operational hydrologist is generally interested in midsize or large basins (hundreds or thousands of $\mathrm{km}^{2}$ ), most distributed models reported in the literature have been applied to small basins (Rogers et al., 1985; Bathurst, 1986) because emphasis is usually placed on scientific understanding of physical processes governing the generation of runoff at the hillslope scale. As has been widely described in the literature (Dunne and Black, 1970; Anderson and Burt, 1990), runoff generation in humid areas is mostly controlled by the spatial variation of saturated areas located near streams. Physically based modeling of the dynamics of these saturated areas requires a detailed description of subsurface flow in the unsaturated zone. Extrapolation of these modeling strategies to midsize or large basins leads either to serious problems of representation of subgrid variability or to unfeasible data and computational requirements (Beven, 1989).

In order to minimize data requirements and to make models applicable to larger basins, several authors have adopted simplifying assumptions, generally based on topographic analysis, which incorporate the concept of variable saturated areas explicitly. O'Loughlin (1981) and Beven and Kirkby (1979) present models based on a topographic wetness index that is used to define the surface-saturated area dynamically. The parsimony of these conceptual models makes them attractive to use, but they still require extensive records of previous events for an adequate calibration (Hornberger et al., 1985).

If physically meaningful parameters are chosen in model formulation, calibration requirements can be reduced accordingly. The goal of the model presented in this paper, called the Distributed Basin Simulator (DBSIM), is to formulate a parameterization of runoff-generation processes more physically based than that of conceptual models, while achieving a computational efficiency that allows for its operational use in midsize basins.

The Distributed Basin Simulator consists of two major components: a runoff generation module and a flow routing module, which are reviewed on the following two sections. Several sensitivity analyses and the application of DBSIM to the case study of the Sieve basin, in Italy, are presented next. A companion paper (Garrote and Bras, this issue) describes the software environment developed for the real-time application of DBSIM and illustrates the advantages of its modular design for interactive use. 


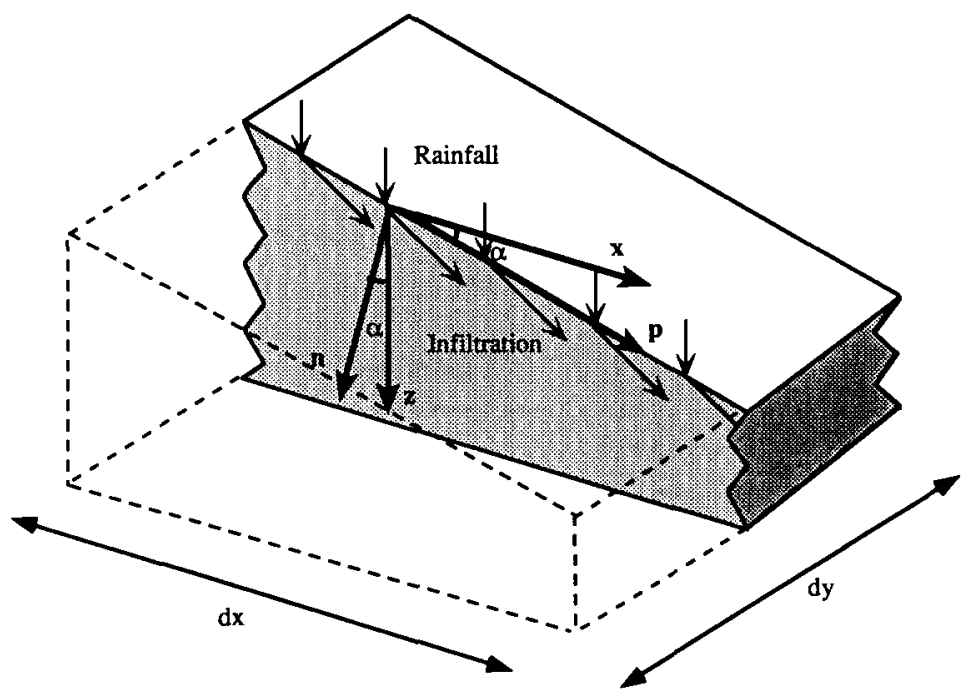

Fig. 1. Coordinate systems used for infiltration analysis on a grid element.

\section{Runoff-generation module}

The goal of the runoff-generation module of DBSIM is to obtain the spatial distribution of the surface infiltration capacity of the basin in order to map the evolution of the saturated areas during a storm event. Saturation develops either near the streams, in areas of convergence of subsurface flow, or in areas where local rainfall intensity exceeds the infiltration capacity of the soil. A kinematic infiltration model developed by Cabral et al. (1992) which emphasizes the role of topography in runoff generation is adapted for its use in distributed modeling by accounting for moisture transfer between elements. The result is a runoff-generation formulation which incorporates two modes of storm runoff generation, exfiltration of subsurface flow and infiltration-excess.

\subsection{Kinematic inflitration model}

The infiltration model adopted in DBSIM is based on the kinematic approximation for unsaturated flow (Beven, 1984). The kinematic model was selected for its simplicity and computational efficiency, which favored its use for real-time distributed computation. The reader is referred to (Cabral et al., 1992) for a detailed description of model conceptualization and development. Only its main results are presented here.

Basin structure and characteristics are represented on the rectangular grid defined by the digital elevation model. Each grid element consists of a soil column of uniform slope angle $\alpha$. Moisture flow is analyzed in the plane perpendicular to the soil surface along the line of maximum slope, as represented in Fig. 1. The local coordinate system follows the line of maximum slope (axis $p$, positive downslope) and the normal to the 


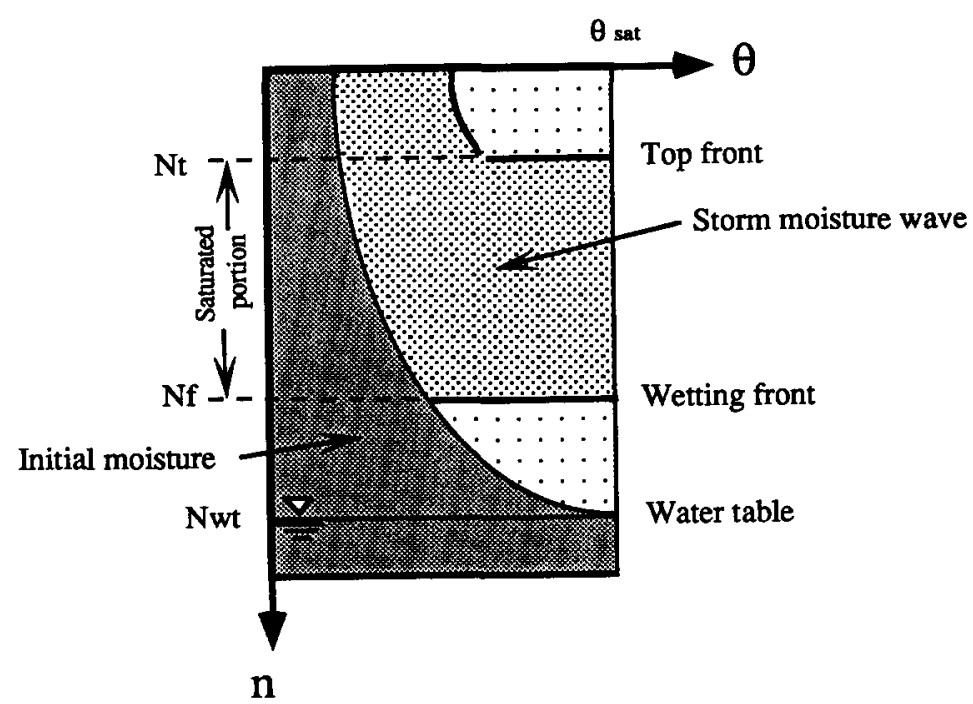

Fig. 2. Vertical moisture profile for a soil column.

soil surface (axis $n$, positive inward). Conditions along the line of maximum slope and in the third spatial dimension are assumed uniform. To represent a possible layering effect, the soil is considered anisotropic, with anisotropy ratio $a_{r}$. The main directions of anisotropy are parallel to the axes of the local coordinate system in every cell, so that $K_{\mathrm{p}}=a_{r} K$, where $K_{\mathrm{p}}$ is hydraulic conductivity in the parallel direction and $K$ in the normal direction. Soil properties follow the Brooks-Corey (Brooks and Corey, 1964) parameterization. The saturated hydraulic conductivity is assumed to decrease exponentially with depth in the normal direction, from a value of $K_{\text {Sat }}^{0}$ at the surface. The exponential decay of hydraulic conductivity is controlled by a parameter, $f$, which is the inverse of a length scale. This parameterization represents the effect of soil compaction and follows the experimental evidence found by Beven (1984).

Under the kinematic approximation, the capillary pressure gradient is neglected and there are no diffusive effects in the penetration of the moisture wave during a storm event. The wetting front is a sharp discontinuity that separates two areas of different moisture content. Above the front, for a constant rainfall rate $R$ smaller than the infiltration capacity of the soil, the steady-state moisture flux in the normal direction, $q$, is $R \cos (\alpha)$. Applying Darcy's law, considering that only the gravitational head gradient $(\cos (\alpha))$ is acting

$$
q=K(\theta, n) \cos (\alpha)=R \cos (\alpha)
$$

Hence $K(\theta, n)$, the normal hydraulic conductivity at depth $n$ for a moisture content $q$, is equal to the rainfall rate $R$. This relationship defines the moisture profile above the front, $\theta(n)$.

The decrease of saturated hydraulic conductivity with depth may lead to the formation of a zone of perched saturation, since moisture content $\theta(n)$ must correspondingly increase with depth to attain constant hydraulic conductivity and 
allow uniform moisture flux along the profile. As the wetting front proceeds downwards, it may reach the level $N *$ where the normal moisture flux equals the saturated hydraulic conductivity and $\theta(N *)=\theta_{\text {Sat }}$, where $\theta_{\text {Sat }}$ is the moisture content at saturation. From that point on, a zone of perched saturation grows, bounded by the wetting front and by a top front. Eventually, the generic moisture profile shown schematically in Fig. 2 develops. The total moisture depth stored in the soil column above the wetting front $M_{\mathrm{t}}$ is divided into an unsaturated area, with moisture depth $M_{\mathrm{u}}$, and a saturated area, with moisture depth $M_{\mathrm{s}}$.

Above the top front, unsaturated infiltration proceeds according to Eq. (1). Between both fronts, the moisture profile is saturated, and the moisture flux $q_{\text {Sat }}$ is the harmonic mean between the saturated hydraulic conductivities at the top and the wetting fronts, affected by the factor $\cos (\alpha)$. Below the wetting front the moisture profile, $\theta_{\mathrm{i}}(n)$, is that corresponding to the initial state before the beginning of the storm. On the long term, this water is kept in equilibrium by a balance of forces between gravitational and capillary head gradients. However, to be consistent with the kinematic assumption, it must be assumed that this moisture profile corresponds to a moisture flux of $R_{\mathrm{j}} \cos (\alpha)$, where $R_{\mathrm{i}}$ is a parameter that characterizes the initial moisture profile.

The kinematic model was developed for uniform rainfall rate $R$. Variable rainfall rates are handled by assuming that water gets redistributed in the soil column in order to attain uniform normal flow. This means that only a single moisture wave propagates downwards, regardless of the variability of rainfall intensity during the storm. An equivalent uniform rainfall rate, $R_{\mathrm{e}}$, is defined as the constant rainfall rate that would have lead to the same moisture content in the unsaturated portion of the column.

Three state variables: the wetting front depth, $N_{\mathrm{f}}$, the top front depth, $N_{\mathrm{t}}$, and the total moisture depth, $M_{\mathrm{t}}$ define the moisture profile. The dynamics of the soil column are governed by a system of first-order differential equations in these three state variables. Under unsaturated conditions the wetting and the top front positions coincide, and their evolution is governed by

$$
\frac{\mathrm{d} N_{\mathrm{f}}}{\mathrm{d} t}=\frac{\mathrm{d} N_{\mathrm{t}}}{\mathrm{d} t}=\frac{\left(R_{\mathrm{e}}-R_{\mathrm{i}}\right) \cos (\alpha)}{\theta\left(N_{\mathrm{f}}\right)-\theta_{\mathrm{i}}\left(N_{\mathrm{t}}\right)}
$$

After perched saturation has developed, the wetting and the top fronts are governed by independent evolution equations

$$
\begin{aligned}
\frac{\mathrm{d} N_{\mathrm{f}}}{\mathrm{d} t} & =\frac{q_{\text {Sat }}-R_{\mathrm{i}} \cos (\alpha)}{\theta_{\text {Sat }}-\theta_{\mathrm{i}}\left(N_{\mathrm{f}}\right)} \\
\frac{\mathrm{d} N_{\mathrm{t}}}{\mathrm{d} t} & =\frac{q_{\text {Sat }}-R_{\mathrm{e}} \cos (\alpha)}{\theta_{\text {Sat }}-\theta\left(N_{\mathrm{f}}\right)}
\end{aligned}
$$

Mass balance considerations provide the evolution equation for the third state variable, $M_{\mathrm{t}}$

$$
\frac{\mathrm{d} M_{\mathrm{t}}}{\mathrm{d} t}=\frac{\mathrm{d} N_{\mathrm{f}}}{\mathrm{d} t} \theta_{\mathrm{i}}\left(N_{\mathrm{f}}\right)+I+\frac{Q_{\text {in }}-Q_{\text {out }}}{A}
$$


The first term of Eq. (5) corresponds to the moisture increment resulting from the vertical displacement of the wetting front. Since $M_{\mathrm{t}}$ is defined as moisture depth above the wetting front, moisture accounting should include the increment due to the incorporation of the initial moisture profile to the reference volume. The second term accounts for surface infiltration, which is discussed in the last part of this Section. The last term corresponds to lateral subsurface inflows, $Q_{\text {in }}$, and outflows, $Q_{\text {out }}$, from the cell owing to interactions with contiguous cells, normalized by the horizontal area of the element, $A$, and is considered next.

\subsection{Moisture transfers among elements}

The kinematic infiltration model is used to quantify moisture movement and storage in a soil column. DBSIM uses the kinematic infiltration model in every grid cell to account for heterogeneities in slope orientation and soil characteristics. In this distributed framework, moisture transfer among grid elements needs to be taken into account in order to represent the spatial structure of subsurface flow at the basin scale.

Two types of moisture transfers among elements are considered in DBSIM. First, the kinematic infiltration model applied to a single grid cell or soil column predicts deviations of infiltrating flow from the vertical even in the case of laterally homogeneous terrain. When the model is applied to a grid cell, the horizontal component of flow produces a net flow of moisture across the downslope boundary, which is transmitted to the adjacent element. We refer to this as the 'intrinsic' or 'local' flow. In addition to that, the application of the gravity-dominated model of infiltration to every element in isolation gives different pressure and moisture distributions in every cell, which in turn lead to horizontal pressure and moisture gradients that drive lateral flow between cells. This second term is called the 'interaction' flow. Both types of moisture transfer are taken into account in a simplified manner.

The local outflow across the downslope boundary of a grid cell, $Q_{\text {loc }}$, is obtained by integrating the horizontal component of the infiltrating flow over the wetted depth along that boundary (Cabral et al., 1992). The resulting expression for the horizontal subsurface flow across a vertical cross-section is applied to evaluate topographically driven outflows from all elements in the basin. Local inflows into a certain element are given by the sum of the local outflows from all the upstream elements draining directly into it. This mechanism accounts explicitly for the role of topography in runoff generation because it concentrates moisture in low-lying cells, possibly leading to development of saturation in the areas of convergence of subsurface flows.

There is also a diffusive mechanism, the interaction flow, which tends to spread moisture away from the areas of perched saturation. Interaction flows are taken into account in DBSIM through a standard finite difference procedure. It is considered that the equations describing front evolution and moisture distribution in every element are valid for the central point of the grid cell. Therefore, the infiltration model provides an estimate of water pressure distribution along the normal to the surface of every element in its central point. Interaction flows are the moisture 


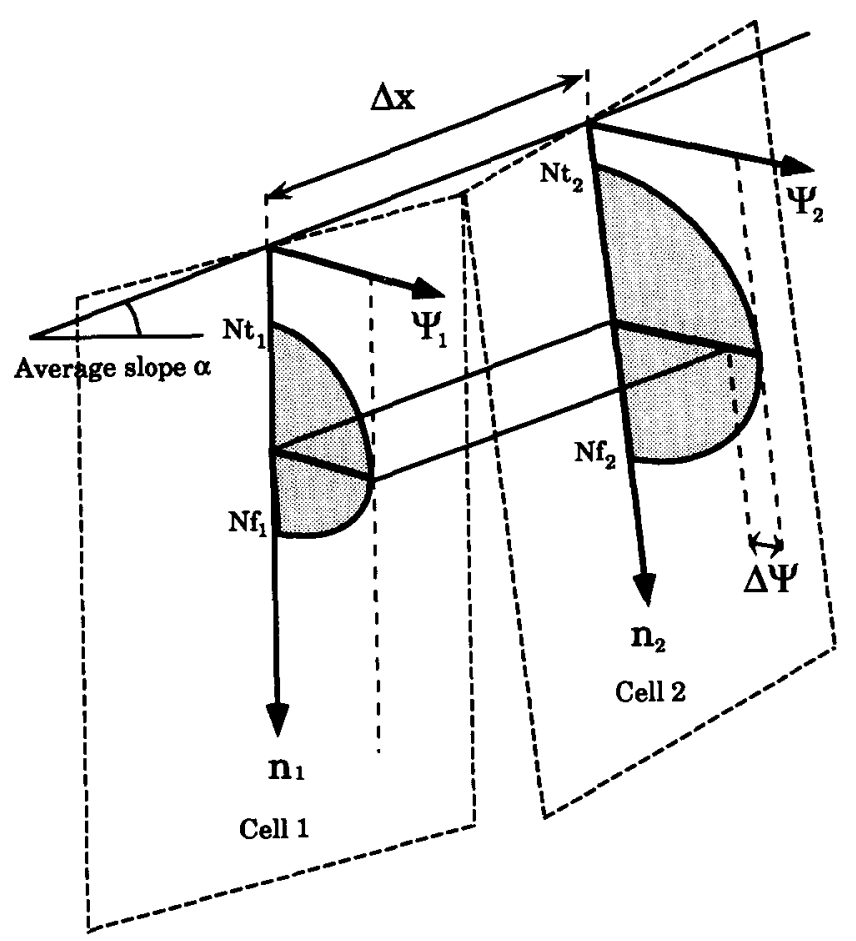

Fig. 3. Schematic of pressure distributions in two contiguous cells.

transfers resulting from lateral gradients of pressure between every two adjacent cells.

The evaluation of interaction flow between two adjacent cells is simplified if an average slope is considered for both cells (Fig. 3). Under that approximation, the vertical distribution of the horizontal gradient, $J_{x}(z)$, along the boundary between two adjacent cells, 1 and 2 , is given by

$$
J_{x}(z)=\frac{\partial \Psi}{\partial x} \approx \frac{\Delta \Psi(z)}{\Delta x}=\frac{\Psi_{2}(z)-\Psi_{1}(z)}{x_{2}-x_{1}}
$$

where $\Psi$ is the pressure head, $z$ represents vertical depth, $x$ represents horizontal distance and

$$
\frac{\partial \Psi}{\partial x}
$$

is approximated as

$$
\frac{\Delta \Psi(z)}{\Delta x(z)}
$$

Neglecting the effect of slope, $\Delta x$ is independent of $z$.

Lateral flow in the horizontal direction, $q_{x}$, is given by Darcy's equation

$$
q_{x}(z)=-K_{x e q}(z) J_{x}(z)
$$


The hydraulic gradient is given by Eq. (6). The equivalent hydraulic conductivity in the horizontal direction, $K_{x e q}(z)$, for the intercell distance, $\Delta x$, is approximated by the equivalent hydraulic conductivity in the parallel direction, which in turn corresponds to two elements of length

$$
\frac{\Delta x}{2}
$$

connected in series

$$
\frac{1}{K_{x \mathrm{eq}}(z)} \approx \frac{1}{K_{p e q}(z)}=\frac{1}{2 K_{p \mathrm{Sat}}^{1}(z)}+\frac{1}{2 K_{p \mathrm{Sat}}^{2}(z)}
$$

Total interaction flow per unit width, $Q_{\text {int }}$, is obtained by integrating Darcy's equation over the saturated depth

$$
Q_{\text {int }}=\int_{z_{\text {inf }}}^{z_{\text {sup }}} q_{x}(z) \mathrm{d} z=-\int_{z_{\text {inf }}}^{z_{\text {sup }}} K_{x \mathrm{eq}}(z) J_{x}(z) \mathrm{d} z
$$

where

$$
z_{\text {inf }}=\operatorname{minimum}\left(\frac{N_{\mathrm{f}}^{1}}{\cos (\alpha)}, \frac{N_{\mathrm{f}}^{2}}{\cos (\alpha)}\right)
$$

and

$$
z_{\text {sup }}=\operatorname{maximum}\left(\frac{N_{t}^{1}}{\cos (\alpha)}, \frac{N_{\mathrm{t}}^{2}}{\cos (\alpha)}\right)
$$

Thus, $Q_{\text {int }}$ is given by

$$
Q_{\text {int }}=\int_{z_{\text {inf }}}^{z_{\text {sup }}} K_{\text {xeq }}(z) \frac{\Psi_{1}(z)-\Psi_{2}(z)}{\Delta x} \mathrm{~d} z
$$

which, dividing in two terms and substituting the limits of integration by the appropriate values, can be expressed as

$$
Q_{\mathrm{int}}=\int_{\frac{N_{\mathrm{t}}^{1}}{\cos (\alpha)}}^{\frac{N_{f}^{1}}{\cos (\alpha)}} K_{x \mathrm{eq}}(z) \frac{\Psi_{1}(z)}{\Delta x} \mathrm{~d} z-\int_{\frac{N_{t}^{2}}{\cos (\alpha)}}^{\frac{N_{f}^{2}}{\cos (\alpha)}} K_{x \mathrm{eq}}(z) \frac{\Psi_{2}(z)}{\Delta x} \mathrm{~d} z
$$

Substituting for the value of $\Psi_{1}$ given by Cabral et al. (1992) in the first term of Eq. (11) and carrying out the integration over $z$

$$
Q_{\text {int }}^{1}=K_{x e q}^{0} \frac{\left(N_{\mathrm{f}}^{1}-N_{\mathrm{t}}^{1}\right)}{\Delta x}\left[\frac{N_{\mathrm{t}}^{1} \exp \left(f N_{\mathrm{f}}^{1}\right)-N_{\mathrm{f}}^{1} \exp \left(N_{\mathrm{t}}^{1}\right)}{\exp \left(f N_{\mathrm{f}}^{1}\right)-\exp \left(N_{\mathrm{t}}^{1}\right)}+\frac{1}{f}+\frac{N_{\mathrm{f}}^{1}+N_{\mathrm{t}}^{1}}{4}\right]
$$

This expression can be interpreted as the moisture outflow per unit width from cell 1 , $Q_{\text {int }}^{1}$, that would be obtained if only pressure head distribution in cell 1 were considered and atmospheric pressure were assumed for cell 2 .

All variables in Eq. (12) refer to values in cell 1. The second term in Eq. (11), $Q_{\text {int }}^{2}$, would correspond to moisture infiow into cell 1 considering only pressure distribution 
in cell 2 and atmospheric pressure in cell 1. The expression is analogous to Eq. (12), substituting 1 by 2 . The net interaction outflow from cell $1, Q_{\text {int }}$, is given by the difference $Q_{\text {int }}^{1}-Q_{\text {int }}^{2}$.

\subsection{Runoff-generation formulation}

Two modes of runoff generation are represented in DBSIM: infiltration-excess runoff and exfiltration of subsurface flow. Both are estimated as final output of the equations described above for the dynamics of the soil moisture profile and lateral moisture transfer. Infiltration-excess runoff is a direct consequence of soil infiltration capacity, designated as $I_{\max }$, which is in turn a function of front position. Exfiltration is a consequence of subsurface flows into a saturated soil column.

Depending on the position of the top and the wetting fronts, the soil column can be in four distinct states, which have different runoff-generating potential. The states, represented in Fig. 4, are discussed below.

Unsaturated - the wetting front is at some depth above the water table, but saturation has not been reached yet $\left(N_{\mathrm{f}}=N_{\mathrm{t}}\right)$. The soil column can only generate infiltration-excess runoff. Infiltration capacity is controlled by the saturated hydraulic conductivity at the surface

$$
I_{\max }=K_{\text {Sat }}^{0} \cos (\alpha)
$$

Perched-saturated - the wetting front has reached the level of saturation, but the top front is still at some depth below the surface $\left(0<N_{\mathrm{t}}<N_{\mathrm{f}}\right)$. The soil column generates infiltration-excess runoff with the same surface infiltration capacity as in the previous state (Eq. 13). Its external behavior is similar to that of an unsaturated cell, but, as the top front approaches the surface, the column becomes closer to saturation and the potential for generating exfiltration increases.

Surface-saturated - the wetting front is at some depth above the water table and the top front is at the surface $\left(N_{\mathrm{t}}=0, N_{\mathrm{f}}<N_{\mathrm{wt}}\right)$. When the top front reaches the surface infiltration capacity is abruptly reduced to the value of the moisture flux in the saturated part of the soil column. Substituting for the value of $q_{\text {Sat }}$ given by Cabral et al. (1992).

$$
I_{\text {max }}=q_{\text {Sat }}=K_{\text {Sat }}^{0} \frac{f N_{\mathrm{f}}}{\exp \left(f N_{\mathrm{f}}\right)-1} \cos (\alpha)
$$

The runoff generation properties of the column are not a function of the surface infiltration capacity, but of the average infiltration capacity of all the saturated zone as a whole, which extends from the surface down to the wetting front. Since hydraulic conductivity decreases with depth, infiltration capacity is significantly lower than that of the unsaturated case. The column may also generate exfiltration, if infiltration plus subsurface flows into the cell exceed subsurface outflows.

Fully saturated - the wetting front has reached the water table depth, $N_{\mathrm{wt}}$, and the top front is at the surface $\left(N_{\mathrm{t}}=0, N_{\mathrm{f}}=N_{\mathrm{wt}}\right)$. The saturated zone extends down to the water table and the soil column behaves effectively as if the water table had reached 

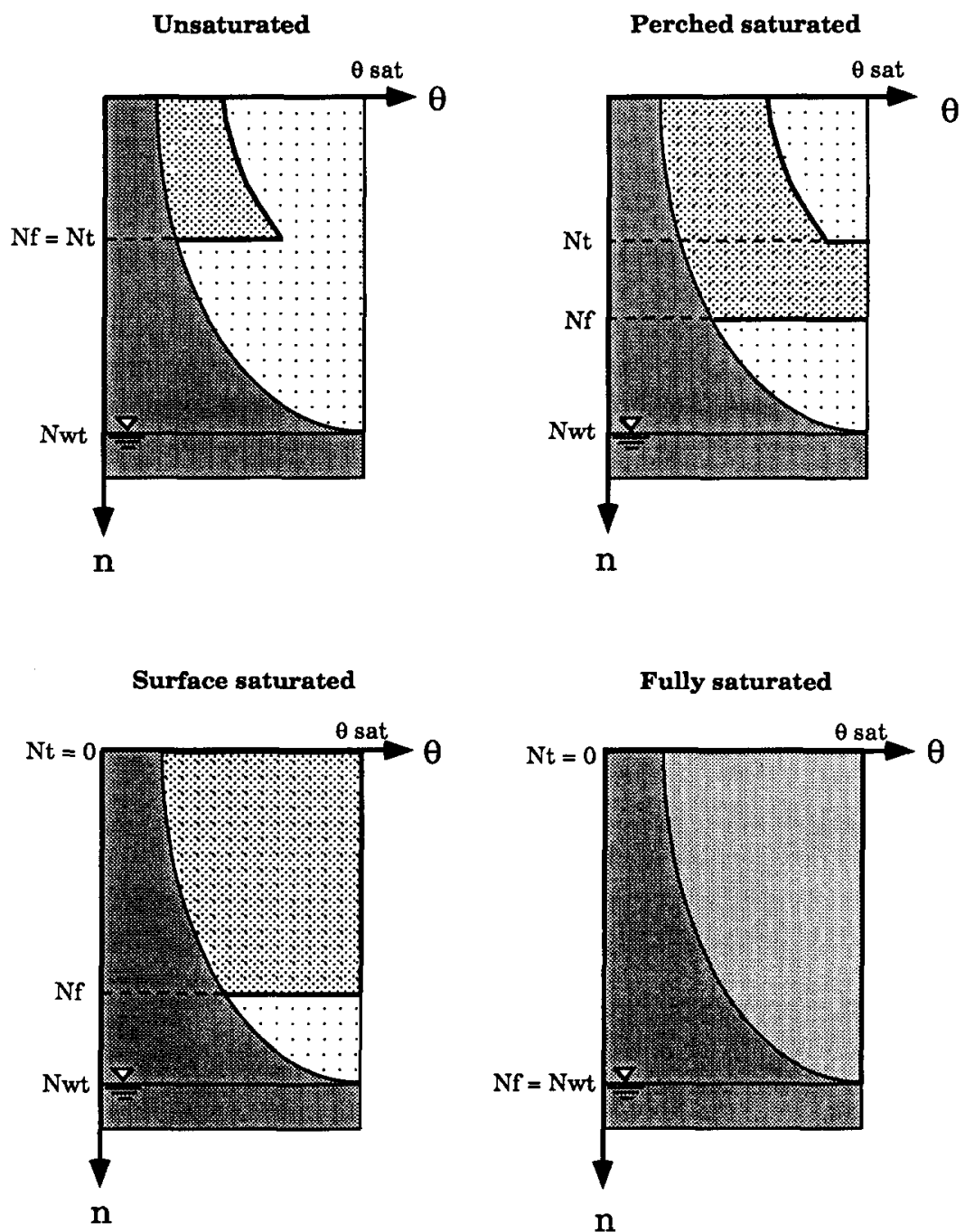

Fig. 4. Four runoff-generation states for a soil column.

the surface. No rainfall from the storm can infiltrate

$$
I_{\max }=0
$$

Therefore, the tendency of fully saturated cells to generate surface runoff and subsurface exfiltration is maximized.

Actual infiltration is obtained by comparing the infiltration capacity of the soil with the rainfall rate. If the rainfall rate is greater than the infiltration capacity, actual infiltration equals the infiltration capacity and infiltration-excess runoff is generated. 
The actual infiltration, $I$, is given in all cases by

$$
\begin{array}{lll}
I=R & \text { if } & R \leq I_{\max } \\
I=I_{\max } & \text { if } & R>I_{\max }
\end{array}
$$

Designating the hortonian or infiltration-excess runoff by $R_{\mathrm{h}}$, it is given by

$$
R_{\mathrm{h}}=R-I
$$

Subsurface exfiltration is generated when the cell is saturated, as a consequence of moisture balance. It is assumed in DBSIM that all moisture inflows accumulate in the area of the soil column affected by the storm, that is, above the wetting front. Therefore, the total moisture content has an upper limit, set by $N_{\mathrm{f}} \theta_{\text {Sat }}$, which corresponds to surface saturation. Whenever the sum of the previous moisture content in the element and the net moisture inflow exceeds the saturation volume above the wetting front, exfiltration is generated. If the cell is not saturated at the surface (unsaturated or perched-saturated states), there is a reservoir above the top front to absorb subsurface moisture inputs, and there is little chance of exfiltration. However, if the cell reaches the surface-saturated state, the limit to the increase of moisture content is set by the speed at which the wetting front progresses downwards, and the potential to generate exfiltration is very high. In this case, according to the moisture balance equation, exfiltration takes place whenever

$$
I+\frac{Q_{\text {in }}-Q_{\text {out }}}{A} \geqslant \frac{\mathrm{d} N_{\mathrm{f}}}{\mathrm{d} t}\left[\theta_{\text {Sat }}-\theta_{\mathrm{i}}\left(N_{\mathrm{f}}\right)\right]
$$

In that condition (surface-saturated cell satisfying Eq. 18), subsurface exfiltration, $R_{\mathrm{ex}}$ is

$$
R_{\mathrm{ex}}=I+\frac{Q_{\text {in }}-Q_{\text {out }}}{A}-\frac{\mathrm{d} N_{\mathrm{f}}}{\mathrm{d} t}\left[\theta_{\mathrm{Sat}}-\theta_{\mathrm{i}}\left(N_{\mathrm{f}}\right)\right]
$$

The total runoff generated by the cell is designated by $R_{\mathrm{f}}$, and it is the sum of infiltration excess runoff $R_{\mathrm{h}}$, given by Eq. (17), and subsurface exfiltration $R_{\mathrm{ex}}$ given by Eq. (19)

$$
R_{\mathrm{f}}=R_{\mathrm{ex}}+R_{\mathrm{h}}
$$

\section{Surface flow routing}

The formulation chosen in DBSIM to represent the distributed response of a basin is the distributed convolution equation

$$
Q^{A}(t)=\int_{A} \int_{0}^{t} R_{\mathrm{f}}(x, y, \tau) h(x, y, t-\tau) \mathrm{d} \tau \mathrm{d} A
$$

where $Q^{A}(t)$ is the resulting hydrograph at the outlet of a basin of area $A, R_{\mathrm{f}}(x, y, t)$ is a function describing the distribution of runoff rate generation per unit area in the basin and $h(x, y, t)$ is the instantaneous response function of the element of area, $\mathrm{d} A$, 
located at coordinates $(x, y)$. In a linear and time-invariant system, the instantaneous response function is constant during the event. Otherwise, the instantaneous response function may vary during the event, according to the varying transport conditions in the drainage network.

In DBSIM, the distributed instantaneous response function is assumed to be a Dirac delta function, with a delay equal to the time of travel from the location of the element to the outlet of the basin. The travel path, $l_{\mathrm{T}}$, for a typical hillslope element consists of a hillslope fraction, $l_{\mathrm{h}}$, corresponding to overland flow or diffuse flow in small gullies, and a stream fraction, $l_{\mathrm{s}}$, corresponding to concentrated channeled flow

$$
l_{\mathrm{T}}=l_{\mathrm{h}}+l_{\mathrm{s}}
$$

To obtain the time of travel, velocities must be defined. Hillslope and stream velocities vary with location and must be strongly correlated with slope, and therefore a spatial distribution of velocities and hence of travel times could be obtained. However, in the absence of a sound basis to estimate the spatial distribution of velocities, mean velocity values were chosen for this work. Travel time is then defined according to the assumption of uniform velocities for both overland and stream flows throughout the basin for a given time, although travel velocities are allowed to vary as the storm progresses, accounting for the changing flow conditions in the streams. If $v_{\mathrm{h}}(\tau)$ is the hillslope velocity and $v_{\mathrm{s}}(\tau)$ is the stream velocity at time $\tau$, the travel time, $t_{\tau}$, for a typical hillslope element is given by

$$
t_{\tau}=\frac{l_{\mathrm{h}}}{v_{\mathrm{h}}(\tau)}+\frac{l_{\mathrm{s}}}{v_{\mathrm{s}}(\tau)}
$$

The time-of-travel formulation allows for a simple computation of the hydrograph at the basin outlet. The instantaneous response function of the basin element located at $(x, y)$ at time $\tau, h_{\tau}(x, y, t)$, is the Dirac delta function given by

$$
h_{\tau}(x, y, t)=\delta\left[\frac{l_{\mathrm{h}}(x, y)}{v_{\mathrm{h}}(\tau)}+\frac{l_{\mathrm{s}}(x, y)}{v_{\mathrm{s}}(\tau)}\right]
$$

An incremental basin response, $q_{\tau}^{A}(t)$ is estimated independently for every time step, $\tau$, routing the runoff generated at every cell

$$
q_{\tau}^{A}(t)=\sum_{(x, y) \in A} R_{\mathrm{f}}(x, y, \tau) h_{\tau}(x, y, t) \Delta x \Delta y
$$

where $R_{\mathrm{f}}(x, y, t)$ is the runoff rate generated in the element at location $(x, y)$ at time $\tau$ and $x y$ is the area of the element. The total basin response at any time $T, Q_{T}^{A}(t)$, is obtained by summing the incremental responses from the beginning of the storm until current time, $T$

$$
Q_{T}^{A}(t)=\sum_{\tau=0}^{\tau=T} q_{\tau}^{A}(t)
$$

This methodology exploits the topographical information in the DEM and allows for 
the quick estimation of the incremental response of any basin once an estimate for hillslope and stream velocities is available at every time step. Currently, travel velocities are estimated in DBSIM by calibration. It is assumed that hillslope and stream velocities are uniform throughout the basin and that the ratio of stream velocity to hillslope velocity is a constant, $K_{\mathrm{v}}$. Therefore

$$
v_{\mathrm{h}}(\tau)=\frac{v_{\mathrm{s}}(\tau)}{K_{\mathrm{v}}}
$$

where $K_{\mathrm{v}}$ is the ratio of stream velocity to hillslope velocity. This simple parameterization, with values of $K_{\mathrm{v}}$ generally between 10 and 15 , has been found to perform well in almost every case tested.

However, for certain basins it was found necessary to account for some nonlinearities in basin response because travel times were a function of the amount of water present in the basin. In these cases, the mean values of hillslope and stream velocities are allowed to vary during the storm. Many authors (Askew, 1970; Kellerhalls, 1970; Mein et al., 1974; Pilgrim, 1977) suggest that a power relation between discharge and flow velocities is valid, at least on a statistical sense. The variable selected to parameterize flow velocities in DBSIM is discharge at the basin outlet $Q^{\circ}$. Basin discharge provides a rough estimate of the conditions in the drainage network, and has the computational advantage of being readily available at all times. Therefore, if basin response is clearly non-linear, the following equation is applied to obtain average hillslope velocities in the basin

$$
v_{h}(\tau)=c_{\mathrm{v}}\left[Q_{\tau}^{\mathrm{o}}(\tau)\right]^{r}
$$

$v_{h}(\tau)$ is the hillslope velocity at time $\tau, Q_{\tau}^{\mathrm{o}}(\tau)$ is the discharge at the basin outlet at time $\tau, r$ is a calibration parameter that controls the degree of non-linearity in the basin and $c_{\mathrm{v}}$ is a calibration coefficient specific for every basin that sets the average velocities as a function of the discharges that can be expected.

\section{Model implementation}

The two modules that compose DBSIM, the runoff-generation module and the surface flow routing module are integrated under a software architecture which formally maintains their independence. Model definition was conditioned to some extent by the requirement to run efficiently in a real-time flood-forecasting framework, and thus, it is expected that the lack of detail in the representation of certain physical processes is to some extent compensated by the possibility to use distributed modeling in this context.

As a result of the feedback process between hydrologic modeling and software development (see Garrote and Bras, this issue), the final structure of DBSIM is particularly well suited for implementation in a real-time interactive computer environment. The state-space formulation of the runoff-generation module provides online evaluation of basin state evolution and allows for the implementation of updating algorithms. In every model cell, the system of first-order differential equations 
governing infiltration is efficiently solved through an explicit finite difference scheme. Interactions among cells are recursively ordered according to the relation 'drains to'. There is no need to solve implicit numerical schemes and therefore execution time is a linear function of the number of grid cells. The model adopted for flow routing allows the quick evaluation of storm hydrographs at any point in the basin, once the travel path and runoff have been obtained for every contributing cell. These processes of local infiltration, distributed runoff generation and surface flow routing are well differentiated and offered to the user as separate simulation tools in an interactive environment. The user can perform on-line analyses, studying the local one-dimensional infiltration, evaluating the runoff generation potential of certain areas or obtaining the outflow hydrograph at any point in the basin.

\section{The Sieve basin case study}

Model performance was analyzed using the Sieve basin as a case study. The Sieve is one of the tributaries of the Arno river, which drains an area of $8000 \mathrm{~km}^{2}$ on the northwest of the Italian peninsula. The confluence of the Sieve and the Arno is located near Florence, where the area of the Sieve catchment is approximately $840 \mathrm{~km}^{2}$. The basin is elongated in shape, with the main river following the Southeast direction. Except in the valleys, dedicated to agriculture, the terrain is forested and mountainous, with an average elevation of $470 \mathrm{~m}$ above sea level. The elevation of the highest peak is $1657 \mathrm{~m}$, and the outlet is at $50 \mathrm{~m}$ above sea level. The climate is Mediterranean. The rainy season lasts from October until April, with peaks in November and February.

\subsection{Sensitivity analyses}

The sensitivity analyses focused on variables that affect runoff generation $((1)$ the inverse length scale that controls the decrease of hydraulic conductivity with depth, $f$, (2) the anisotropy ratio, $a_{\mathrm{r}}$ and (3) the initial depth of the water table, $N_{\mathrm{wt}}$ ) and on routing parameters ((1) the ratio of hillslope and stream velocity, $K_{\mathrm{v}},(2)$ the coefficient $c_{\mathrm{v}}$ and (3) the exponent of the non-linear law, $r$ ). Only the main results of the analyses are presented here. The interested reader is referred to Garrote and Bras (1993) for a detailed discussion. Model sensitivity to runoff-generation parameters is presented first, followed by the study of flow routing parameters.

The parameter values considered in the analysis of the runoff generation are shown in Table 1. The parameters $f$ and $a_{\mathrm{r}}$ were assumed uniform throughout the basin, while the initial position of the water table, $N_{\mathrm{wt}}$, was allowed to vary, according the physical model of subsurface saturated flow of (Cabral et al., 1990). Four values of the inverse scale length, $f$, and the anisotropy ratio, $a_{\mathrm{r}}$, were considered.

The initial state was defined by the initial wetting front depth, $N_{\mathrm{f}}(x, y)$, the water table depth, $N_{\mathrm{wt}}(x, y)$, and the initial moisture content of the soil column above the water table, expressed in terms of the parameter $R_{\mathrm{i}}(x, y)$. The wetting front was assumed to be at the surface at the beginning of the storm. Initial water table 
Table 1

Parameter values for runoff generation analysis

\begin{tabular}{lllll}
\hline Parameter & Values & & & \\
\hline Parameter $f\left(\mathrm{~mm} \mathrm{~h}^{-1}\right)$ & $1 \times 10^{-4}$ & $3 \times 10^{-4}$ & $5 \times 10^{-4}$ & $7 \times 10^{-4}$ \\
Anisotropy ratio $a_{\mathrm{r}}$ & 1 & 10 & 100 & 500 \\
Initial state & Dry & Average & Wet & \\
\hline
\end{tabular}

positions were generated using the model described by (Cabral et al., 1990), which considers Darcian water movement in the saturated zone below the water table. The model gives the water table position for which the baseflow drained from the basin is in equilibrium with a long-term recharge rate, assumed uniform throughout the basin. Three long-term recharge rates were used, corresponding to wet, average and dry states. The parameter $R_{\mathrm{i}}$ is obtained at every location by requiring soil moisture to reach saturation at the depth of the water table.

Basin responses for different parameter values are illustrated in Figs. 5-7. Runoff is decomposed according to its different possible origins. Two basic types of runoff are considered: infiltration-excess runoff and subsurface exfiltration. Since basin state dynamics are also important, the plots differentiate between runoff generated in the areas of the basin which are permanently saturated (stream areas or areas where the initial water table is at the surface) and runoff generated in the areas of the basin which become temporarily saturated during the storm. In general, runoff generated in permanently saturated areas is not sensitive to parameter values, and is only determined by the basin initial state. Runoff generated in the rest of the basin can be extremely sensitive to parameter values, accounting for the visible differences at the basin scale.

The lowest part of the runoff plots (dotted line) represents exfiltration generated in permanently saturated areas. This area is barely noticeable in most plots because the contribution of this type of runoff to the global response is very small, in spite of the fact that the fraction of the basin which is saturated is important in some cases. The next layer (between the dotted and the dashed line) represents exfiltration generated in areas that have become temporarily saturated. The third layer (between the dashed and the dash-dotted line) represents infiltration-excess runoff generated in areas permanently saturated. Since infiltration capacity here is null, these areas usually account for the most important fraction of total runoff generation. The last fraction (between the dash-dotted line and the solid line) represents infiltration-excess runoff generated in the rest of the basin, and includes both the unsaturated and surfacesaturated areas.

These results suggest that the representation of hillslope processes is still incomplete, since the fraction of exfiltration generated in saturated areas will certainly be greater in a real basin. This poor result is a distortion introduced by the event-based approach adopted as modeling strategy. Given the definition of the initial state with the wetting front at the surface, it takes some time until the storm moisture wave simulated by the model grows and reaches the permanently saturated areas, whereas in nature these areas are contributing baseflow from the beginning of the storm. This 

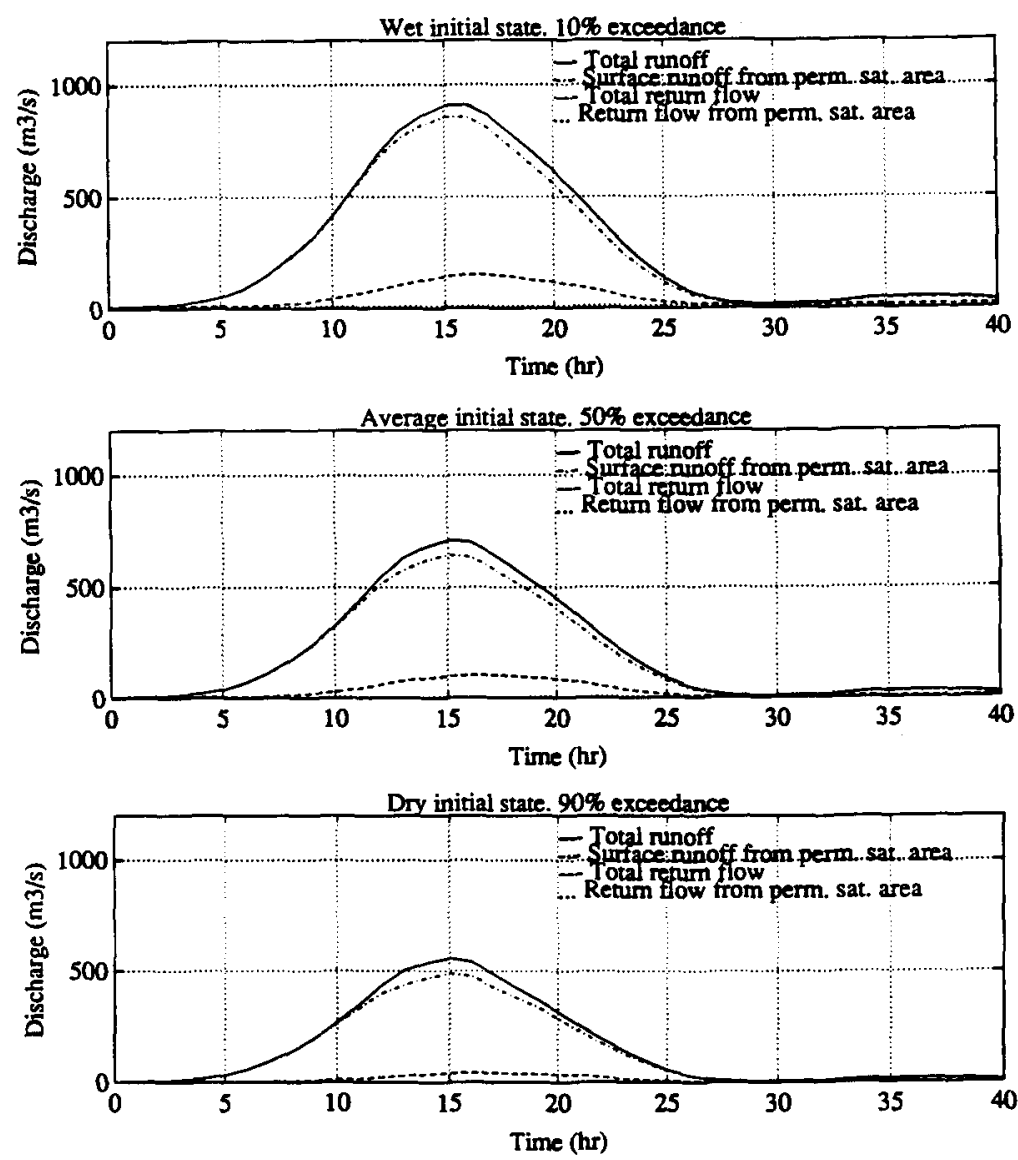

Fig. 5. Decomposition of basin response into different modes of runoff generation for initial moisture states with 10,50 and $90 \%$ probability of exceedance. The results correspond to parameter $f$ equal to $5 \times 10^{-4} \mathrm{~mm}^{-1}$ and anisotropy ratio equal to 10 .

misrepresentation cannot be corrected by simulating a longer period, prior to the beginning of the storm, because for interstorm periods the kinematic approximation is not applicable at all. The effect is partly overcome by adding a baseflow term to the final hydrograph, which represents the quasi-equilibrium subsurface moisture outflow corresponding to the condition at the beginning of the storm.

Sensitivity to the initial state is shown in Fig. 5, where basin responses to wet, average and dry initial states are shown. The model was sensitive to the position of the water table in all cases, but it was observed that different combinations of the other parameters can greatly enhance this sensitivity. In general, the effect of $f$ on the sensitivity to the position of the water table was greater than that of the anisotropy ratio. The definition of the basin initial state is crucial from the point of view of runoff generation, since it is the most important factor governing basin response. Greater 

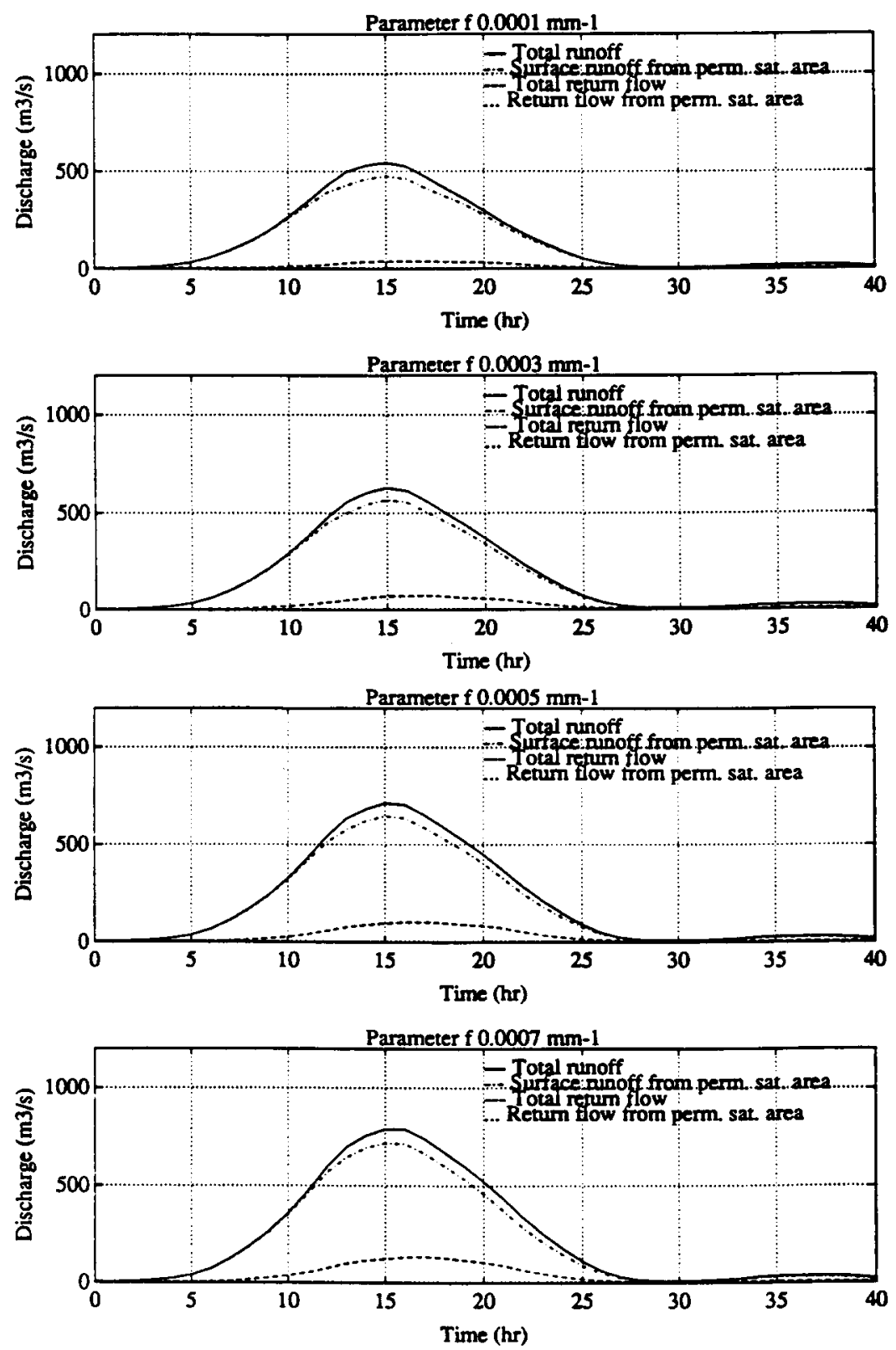

Fig. 6. Decomposition of basin response into different modes of runoff generation for parameter $f$ equal to $1 \times 10^{-4}, 3 \times 10^{-4}, 5 \times 10^{-4}$ and $7 \times 10^{-4} \mathrm{~mm}^{-1}$. The results correspond to anisotropy ratio equal to 10 and initial moisture state with $50 \%$ probability of exceedance. 

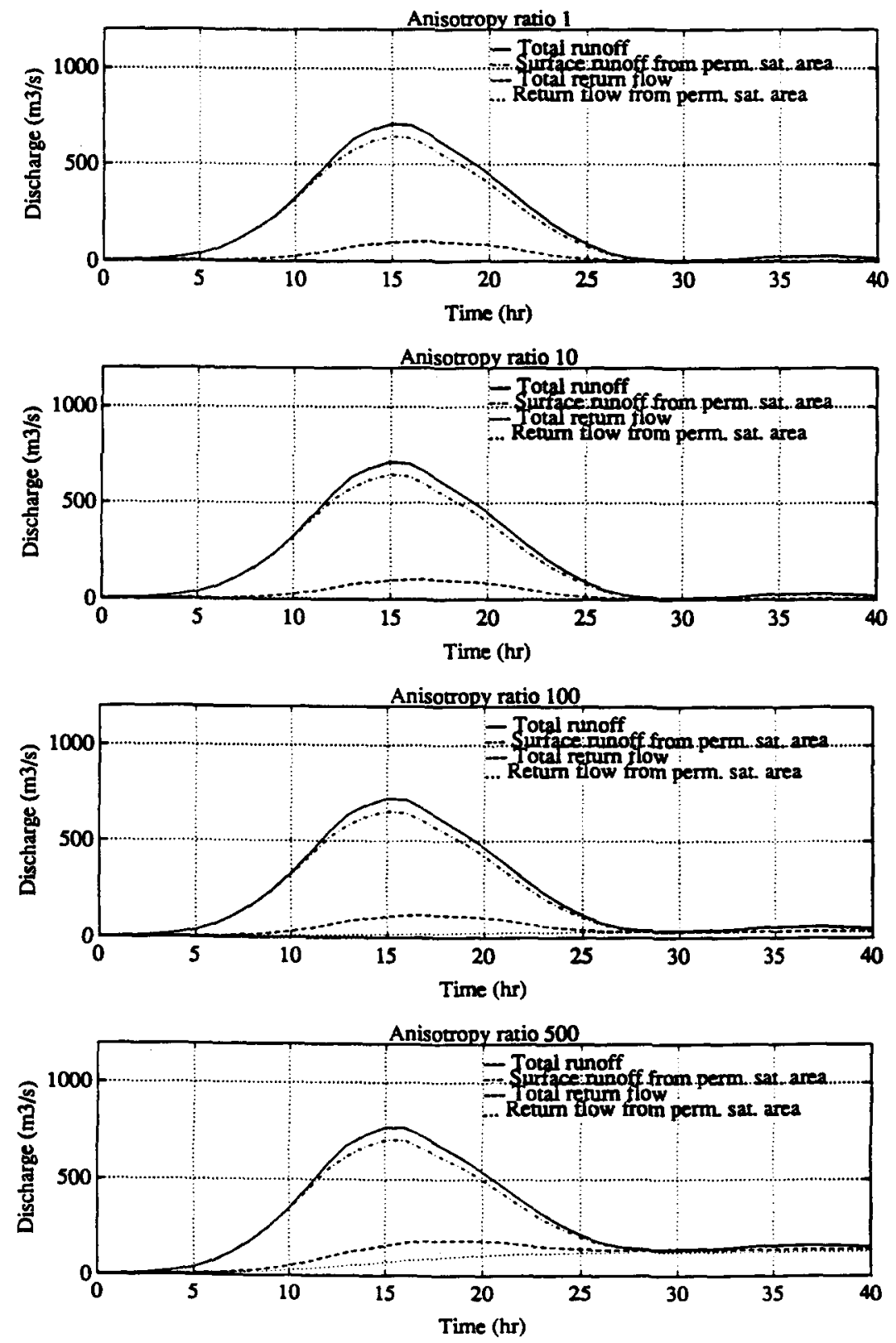

Fig. 7. Decomposition of basin response into different modes of runoff generation for anisotropy ratio equal to $1,10,100$ and 500 . The results correspond to parameter $f$ equal to $5 \times 10^{-4} \mathrm{~mm}^{-1}$ and initial moisture state with $50 \%$ probability of exceedance. 
Table 2

Parameter values for the sensitivity analysis of surface flow routing

\begin{tabular}{lcccc}
\hline Parameter & Values & & & \\
\hline Velocity ratio $K_{\mathrm{v}}$ & 5 & 10 & 15 & 20 \\
Coefficient $c_{\mathrm{v}}\left(\mathrm{m} \mathrm{h}^{-1}\right)$ & 100 & 200 & 400 & 600 \\
Exponent $r$ & 0.0 & 0.1 & 0.2 & 0.3 \\
\hline
\end{tabular}

long-term recharge rates (wet states) lead to a greater proportion of the basin with water table at the surface and shallower water table depths in the unsaturated areas. Basin response is directly affected by the fraction of the basin which is initially saturated. Moreover, the tendency of the saturated area to expand during the storm is greater for shallow water table positions, which are correlated with wet initial states.

An important part of the sensitivity of the total hydrograph to the inverse scale length, $f$, comes from exfiltration generated in the areas of the basin which become saturated during the storm (Fig. 6). Also, there is a different response in infiltrationexcess runoff, but it is comparatively smaller. The parameter $f$ defines the level at which the wetting front will reach saturation for a given infiltration rate. As $f$ becomes greater, saturation is reached at a shallower depth, and therefore a greater number of cells become saturated. The infiltration capacity in those cells is significantly reduced and more surface runoff is generated, but the most important effect is that when a certain area becomes saturated all the subsurface flow converging into it exfiltrates. The mechanisms through which the parameter $f$ increases runoff generation are: (1) increasing the surface of locally saturated areas; (2) enhancing the production of exfiltration in these locally saturated areas.

As shown in Fig. 7, model sensitivity to the anisotropy ratio is smaller than sensitivity to the parameter $f$. In general, only the case $a_{\mathrm{r}}=500$ appears to be significantly different from the rest. The cases of $a_{\mathrm{r}}=1$ and $a_{\mathrm{r}}=10$ are almost equal. The sensitivity of the total hydrograph to the anisotropy ratio is from the exfiltration generated in permanently saturated areas (dotted line in the plots). The mechanism through which the anisotropy ratio increases runoff generation is by enhancing the production of exfiltration in permanently saturated areas. The response time of runoff generated through this mechanism is much slower than other runoff components of the basin. The anisotropy ratio controls lateral flow between elements, and, therefore, its main influence is through the effect of subsurface exfiltration. As shown in Fig. 7, the portion of exfiltration generated in the areas which become saturated during the storm is approximately constant for different anisotropy ratios. Exfiltration is mainly controlled by the parameter $f$, because local saturation is mostly a transient effect, and the response of subsurface flow is so slow that there is no time to accumulate enough convergence of subsurface flow in the temporarily saturated areas. The effect of the anisotropy ratio is seen in the areas which are permanently saturated because, in that case, there is enough time for subsurface flow to accumulate.

Another set of computer runs was used to test sensitivity to surface routing parameters. The model was run with a unique set of runoff-generation parameters 

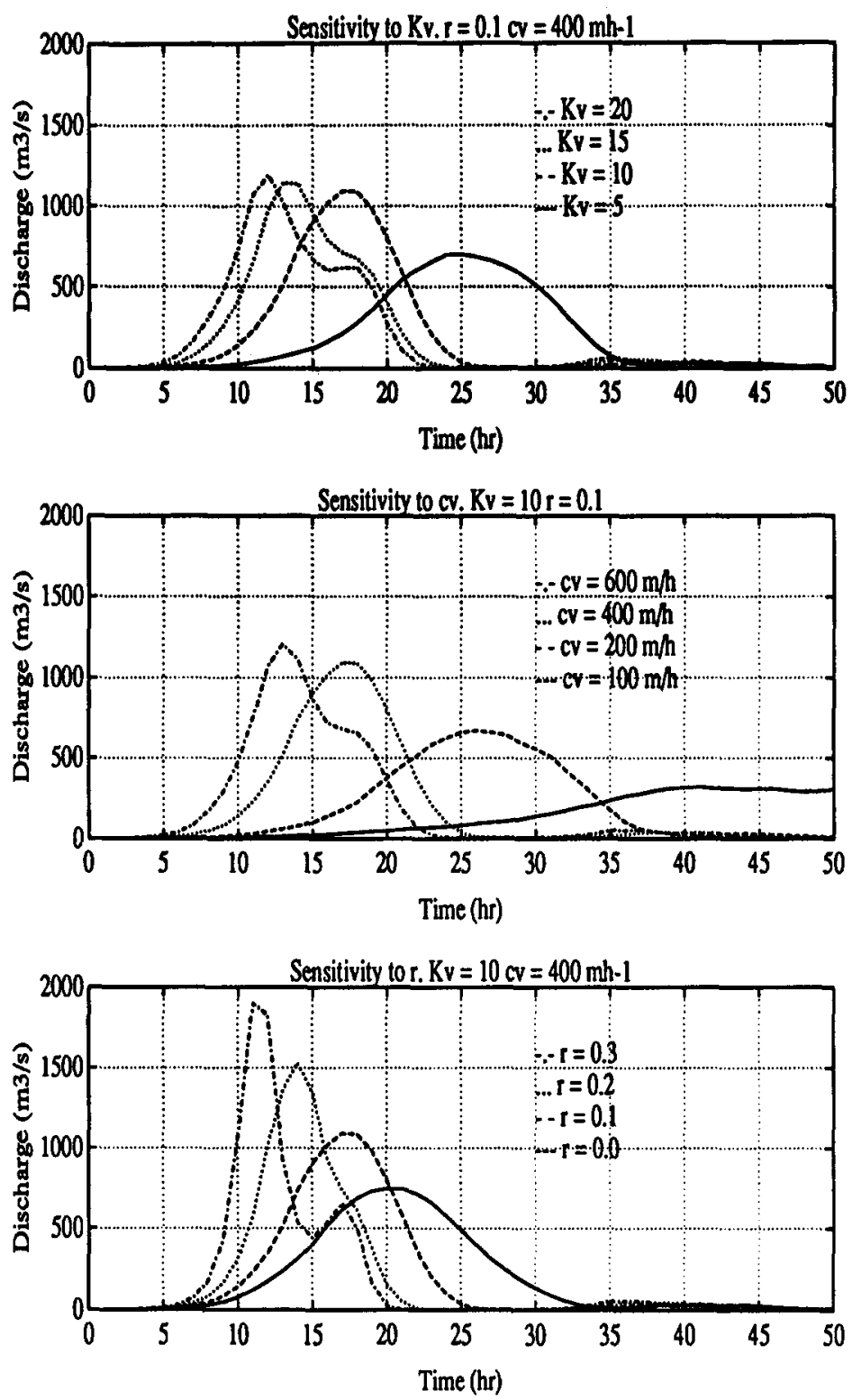

Fig. 8. Sensitivity of basin response to surface flow routing parameters.

and the surface-routing parameters were changed to explore model sensitivity. The parameters tested were the ratio of stream velocity to hillslope velocity, $K_{\mathrm{v}}$, the coefficient $c_{\mathrm{v}}$ and the exponent $r$ in the power law relating hillslope velocity and discharge at the outlet (Eq. 28). The numerical values of the parameters are shown in Table 2. 
Model sensitivities to the ratio of velocities, $K_{\mathrm{v}}$, to the coefficient $c_{\mathrm{v}}$ and to the exponent $r$ are presented in Fig. 8. Sensitivity is very high in all cases and hydrograph shapes are greatly affected by the routing parameters. The effects of $K_{\mathrm{v}}$ and $c_{\mathrm{v}}$ are very similar, because both represent uniform increments in travel velocities. In the case of $K_{\mathrm{v}}$, the increments only correspond to stream velocities, while in the case of $c_{\mathrm{v}}$, the increments correspond to both stream and hillslope velocities. In both cases the effect of decreasing the parameter value is to dampen the basin response, delaying the occurrence of the peak and smoothing the shape of the hydrograph. It also appears that stream velocities are dominant in configuring basin response, at least for the range of parameter values tested here.

The effect of the exponent $r$ is somewhat different from that of $K_{\mathrm{v}}$ or $c_{\mathrm{v}}$. Large values of $r$ narrow the shape of the hydrograph significantly. The explanation is that increments in $r$ represent greater increments of travel velocities when the discharge is large, and therefore, the velocities are greater around the peak and lower at the beginning and the end of the hydrograph. This is a good criterion to identify nonlinearities in basin response.

\subsection{Model calibration and evaluation}

Data for model calibration were taken from Cabral et al. (1990), who applied a preliminary version of DBSIM to the Sieve basin. The DEM available for the Sieve had a resolution of $1 \mathrm{~m}$ in elevation and a cell size of $400 \times 400 \mathrm{~m}^{2}$. Data about physical basin parameters and several observed storms were also available. Rainfall data were available from a limited number of recording stations at a temporal resolution of $20 \mathrm{~min}$. Streamflow data were available from a stage gauge located at Fornacina, near the confluence of the Sieve with the Arno. The gauge did not operate continuously. It recorded water levels only during storm periods which were considered to be potentially dangerous. Hence no interstorm flow data were available. A total of ten storm events were selected to analyze model performance. Five storms were used to calibrate the model against observed data. The resulting parameter set was then tested using the other five storms.

Most model parameters were estimated using available information on topography and soil types. The DEM provided information on slopes and drainage directions, following the methodology of analysis proposed by Tarboton et al. (1991). Soil parameters were estimated from a study by Busoni et al. (1986), which included the characterization of 17 soil types for the Sieve basin, defining saturated hydraulic conductivity and porosity. Other Brooks-Corey parameters were estimated from published values in the literature for soils of similar conductivity and texture. Only a minimum number of parameters were fixed by calibration: $f$ and $a_{\mathrm{r}}$ for runoff generation and $c_{\mathrm{v}}$ and $K_{\mathrm{v}}$ for surface flow routing. The goal of calibration was to obtain reasonable parameter values that produced the best collective agreement between computed and observed streamflow in the events reserved for calibration.

During the sensitivity analyses, $f$ and $a_{\mathrm{r}}$ were found to be relatively independent. Parameter $f$ controls the volume of infiltration-excess runoff and $a_{\mathrm{r}}$ the volume of 
Table 3

Parameter set which gave the best fit

\begin{tabular}{lc}
\hline Parameter & Value \\
\hline Parameter $f\left(\mathrm{~mm}^{-1}\right)$ & $7 \times 10^{-4}$ \\
Anisotropy ratio $a_{\mathrm{r}}$ & 500 \\
Velocity ratio $K_{\mathrm{v}}$ & 12.75 \\
Velocity coefficient $c_{\mathrm{v}} \mathrm{km} \mathrm{h}^{-1}$ & 0.408 \\
Exponent $r$ & 0 \\
\hline
\end{tabular}

subsurface runoff. The difference is observable, since infiltration-excess runoff is directly related to rainfall, whereas subsurface runoff may occur after precipitation has finished. Therefore, the tail of the observed hydrograph can be used to obtain an estimate of short-term subsurface runoff adjusting the value of $a_{\mathrm{r}}$. The other component of runoff was then estimated by adjusting the value of $f$. The process required a thorough analysis of every storm available, to discriminate between direct and subsurface runoff. It was complicated because observations of runoff were usually discontinued when water levels returned to normal values and, therefore, only a small fraction of the tails of the hydrographs was available.

The initial state of the basin should be either estimated from measurements of surface moisture distribution or computed with a long-term hydro-climatological model that includes evapotranspiration. In practice, the only data available for the Sieve basin were precipitation series at the recording stations, which were insufficient to define a reasonable initial state. The solution adopted was to estimate the initial state as another unknown by calibration. Model definition of the initial state is a function of just one variable, the uniform recharge rate that is in long-term equilibrium with observed interstorm flows in the basin. Long-term records of streamflow in the Arno river allow the estimation of the distribution of monthly averages of interstorm flow in the Sieve. For every month, a value of interstorm streamflow can be assigned to a given probability of exceedance. Flows with low probability of exceedance represent wet states and flows with high probability of exceedance represent dry states. For every month three probability levels were selected: $0.1,0.5$ and 0.9 , and the corresponding interstorm flows were obtained (Cabral et al., 1990).

Three initial states were thus defined for every month, and calibration was accomplished for all three states of the corresponding month in every storm. This

Table 4

Calibration: summary of results

\begin{tabular}{llllll}
\hline Storm & Rainfall $(\mathrm{mm})$ & Peak & Shape & Initial state & Result \\
\hline February 1977 & 33.04 & Fair & Fair & $50-10 \%$ & Fair \\
January 1979 & 46.36 & Good & Good & $50 \%$ & Good \\
November 1982 & 74.45 & Fair & Good & $90 \%$ & Good \\
February 1983 & 38.34 & Good & Very poor & $50 \%$ ? & Poor \\
January 1985 & 25.28 & Good & Fair & $90-50 \%$ & Fair \\
\hline
\end{tabular}




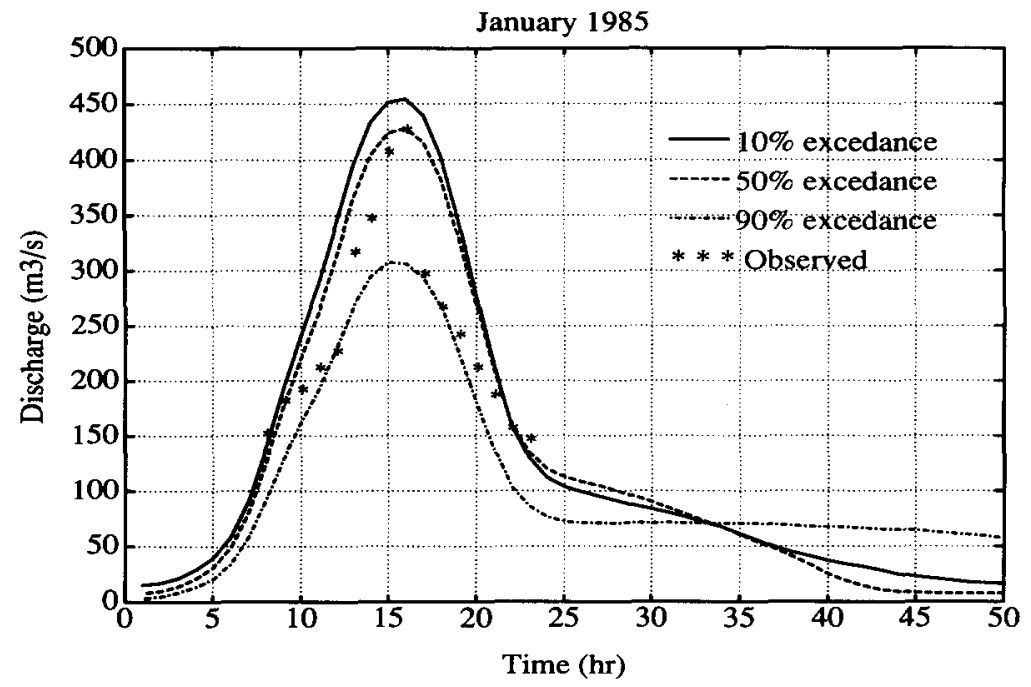

Fig. 9. Observed and simulated hydrographs for the storm of January 1985. Simulated results correspond to initial moisture states with 10,50 and $90 \%$ probability of exceedance.

approach weakens the soundness of the calibration process, since much of the variability in basin response can be explained through different initial conditions, but no other independent means of estimating the initial state were available.

The scheme followed in the calibration of the time of travel was much simpler because the hypothesis of uniform hillslope and stream velocities throughout the basin reduces the complexity of the problem. The drainage network was defined independently of the calibration. The network proposed by Cabral et al. (1990), based on studies of Carlà et al. (1987), was adopted. The network is generated from the DEM following drainage directions and using a threshold contributing area of eight elements, which corresponds to $1.28 \mathrm{~km}^{2}$. The resulting network had 1084 stream elements out of a total of 5252 for the whole basin; this high density of stream elements is due to the coarse spatial resolution of the DEM available.

Travel velocities are given by Eqs. (27) and (28). The parameters to estimate are the coefficient $c_{\mathrm{v}}$ and the exponent $r$, and the ratio of stream velocity to hillslope velocity, $K_{\mathrm{v}}$. The exponent $r$ was initially set to 0 , since there was no special reason to expect

Table 5

Verification: summary of results

\begin{tabular}{lcllll}
\hline Storm & Rainfall $(\mathrm{mm})$ & Peak & Shape & Initial state & Result \\
\hline December 1968 & 31.77 & Poor & Fair & $90-50 \%$ & Fair \\
January 1969 & 41.56 & Good & Good & $90 \%$ & Good \\
December 1975 & 52.67 & Poor & Fair & $90 \%$ & Poor \\
December 1976 & 26.61 & Fair & Fair & $<10 \%$ & Fair \\
November 1987 & 103.03 & Fair & Very poor & $>90 \% ?$ & Poor \\
\hline
\end{tabular}




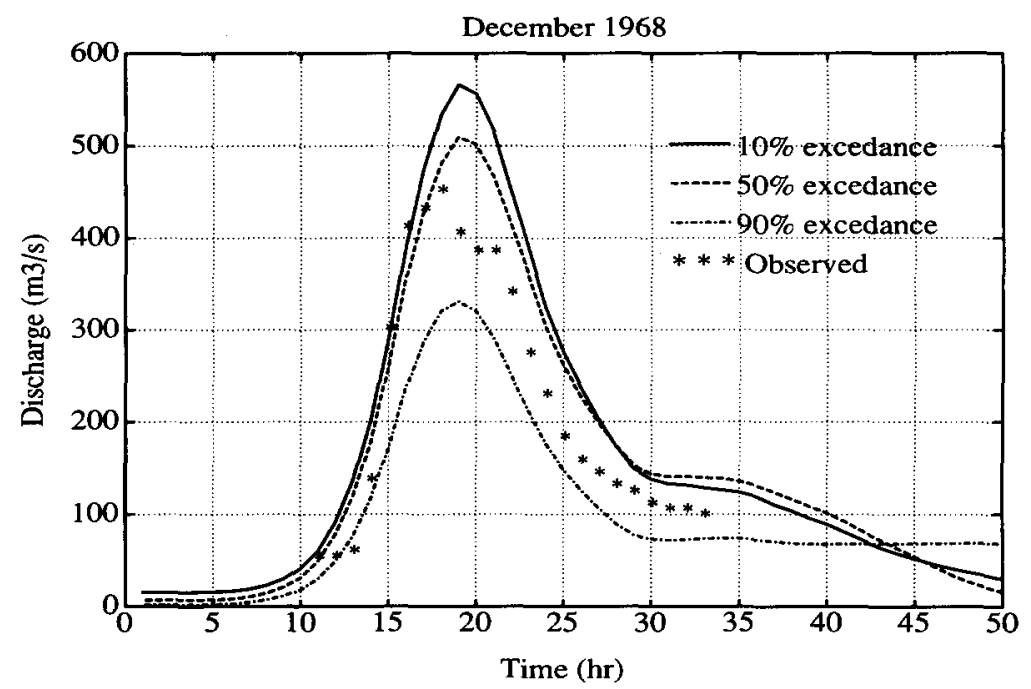

Fig. 10. Observed and simulated hydrographs for the storm of December 1968. Simulated results correspond to initial moisture states with 10,50 and $90 \%$ probability of exceedance.

non-linearity. The estimation of $c_{\mathrm{v}}$ and $K_{\mathrm{v}}$ was based on the comparison of the general features of the hydrograph, notably the time at which the main peak occurs.

A trial-and-error process was followed during calibration. Once satisfactory values for the routing parameters were obtained, different combinations of $f$ and $a_{\mathrm{r}}$ were tried until acceptable results were obtained. The objective of the calibration was to obtain a rough estimate of the approximate values of the parameters, since a mathematical parameter optimization could not be carried out because of a lack of enough streamflow information.

The selection of the best parameter set was made based on a comparison of the observed data with the simulations corresponding to the three initial conditions. The objective was to reproduce qualitative features of the observed flow, such as peak discharge, time to peak and baseflow recession. Since the initial state was not known, there was one degree of freedom in the results. The evaluation of the results was subjective, and the assumption was made that the storms available for calibration should be comprised between the two limiting initial conditions, $10 \%$ and $90 \%$ probability of exceedance, respectively. The parameter set which gave the best fit is listed in Table 3. It is remarkable that the best fit is obtained with an anisotropy ratio of 500 .

A subjective evaluation of the calibration results is presented in Table 4. Two qualitative variables are included in the analysis: peak and shape. Peak includes the ability to reproduce the values and especially the timing of the observed peak discharge. Timing is considered more important than absolute value, because the simulations cover a wide range of possible values, owing to the uncertainty of the initial state. Shape is an overall evaluation of how the simulated hydrographs reproduce the total runoff volume and its distribution in time. The table also includes an estimation 


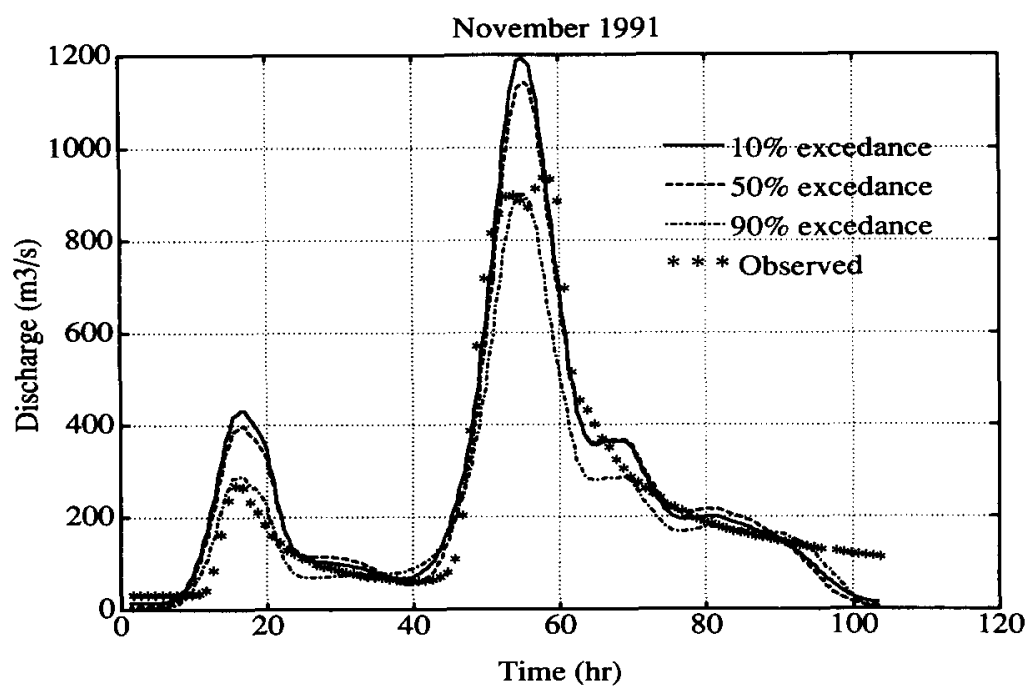

Fig. 11. Observed and simulated hydrographs for the storm of November 1991. Simulated results correspond to initial moisture states with 10,50 and $90 \%$ probability of exceedance.

of the initial state that leads to the best fit between observed and simulated hydrographs.

Peak discharge and time to peak are reasonably well reproduced. However, the overall shape of the simulated hydrographs is not as well preserved. Total runoff volumes obtained in the simulations appear to be larger than observed ones, but no conclusive assessment can be made owing to the lack of continuous streamflow recording. As an illustration of the type of results obtained, model results for the storm of January 1985 are shown in Fig. 9.

The predictive capability of the calibrated model was tested in the verification step using other five storms. The model was run with the optimum parameter set obtained in the calibration, and results were compared with observed discharge data.

A subjective evaluation of the results, considering the same criteria used in the calibration step, is presented in Table 5. Although differences between observed and simulated hydrographs are apparent, model performance with the verification set is no worse than with the calibration set, which suggests that the calibration process was successful in the sense of estimating the best parameter set for the basin. If these other five storms were included in a new calibration process, the values of the parameters probably would not change very much.

Compared with the calibration set, a greater dispersion with respect to the initial state is observed in the verification set. While the December 1976 storm appears to correspond to a very wet initial state, the storms of January 1969 and December 1975 suggest a very dry initial condition. In general, model performance is acceptable in all storms except in November 1987. An example of the results obtained is presented in Fig. 10 for the storm of December 1968.

After the verification step was finished, data were received corresponding to a new 
storm in the Sieve basin. The storm took place in November 1991, and the quality of the data was significantly better than that of the previously available storms. Rainfall information was still obtained from a rain gauge network, but network density was considerably greater. A total of 30 rain gauges were available, and six of them were located inside the Sieve basin. Total rainfall depth in the basin was $111 \mathrm{~mm}$. Streamflow data were also of greater quality, since continuous recording of streamflow was available.

The model was run for this recent storm, and the results are shown in Fig. 11. The results are very encouraging. The model reproduces the shape of the hydrograph with reasonable accuracy, and model performance is better than in the other cases of the verification set and even the calibration set. The simulation suggests a relatively dry initial condition, which is consistent with the time of the year (beginning of the rainy season). The timing of the rising and the falling limbs of the hydrograph is acceptable, and the adjustments of the interstorm periods are excellent, specially if we consider that poststorm baseflow recession is generated through physically based mechanisms using the same parameters as other model processes, and not through conceptual recession equations with specific parameters to fit baseflow recession.

Although such good model performance with a good data set could very well be just a serendipitous coincidence, it strongly suggests that model performance can be considerably improved with better data. In particular, distributed rainfall information obtained from radar maps is crucial to evaluate the response of the different areas of the basin to irregularly distributed rainfall.

\section{Concluding remarks}

The Distributed Basin Simulator, a rainfall-runoff model for real-time flood forecasting in midsize and large basins is presented. DBSIM accepts distributed rainfall input and uses intensively the topographical information encoded in the DEM, as well as other types of georeferenced information. It accounts for the effects of slope, anisotropy and soil heterogeneity on subsurface flow and runoff production through an analytical formulation of local infiltration processes. Basin-scale processes of surface and subsurface water transport are also represented through discretized schemes on a rectangular grid. The model emphasizes computational efficiency for real-time use, although the main features of topography-based runoff generation and transport processes are believed to be well represented.

DBSIM was tested on a $840 \mathrm{~km}^{2}$ watershed in the Arno basin (Italy), under the average conditions that can be expected in a practical application, using a short record of ten events. Model performance was first analyzed through extensive sensitivity analyses followed by a calibration and verification exercise. The sensitivity analyses gave an appreciation of the role of model parameters in the generation of basin response. The parameter $f$ was found to control mostly the volume of infiltration-excess runoff, whereas the anisotropy ratio $a_{\mathrm{r}}$ was found to control the volume of subsurface exfiltration. However, actual calibration values obtained for these parameters cast some doubts over the possibility of estimating them exclusively from 
physical principles, without proper calibration. The definition of the basin initial state was shown to be of extreme importance for model performance. The calibration process illustrated the model ability to reproduce observed hydrographs and the verification step tested the model as a predictive tool. Results of the verification step were encouraging, showing that the model can be calibrated to acceptable levels of performance with a limited data set.

Although there are other distributed models that offer more detailed representations of physical processes, DBSIM provides a realistic alternative for realtime distributed simulation at large scale. Even when applied to basins of more than 50000 cells, the run time performance is entirely satisfactory (about $3 \mathrm{~min}$ per time step on a DEC 3100 or a SUN SPARCstation 10). The authors are confident that the benefits resulting from the inclusion of detailed topographical information and distributed rainfall input in real-time flood forecasting can compensate for the unavoidable simplifications in the formulation imposed by current limitations in computer performance.

\section{Acknowledgments}

This research was supported by the US Army Research Office (Grant DAALO-389-K-0151), the Arno Project of the National Research Council of Italy, the National Weather Service (cooperative agreement NA86AA-D-HY123) and the National Science Foundation (Grant CES-8815725). The first author was sponsored by a postdoctoral scholarship of the Spanish Ministry of Education.

\section{References}

Anderson M.G. and Burt, T.P., 1990. Subsurface runoff. In: M.G. Anderson and T.P. Burt (Editors), Process Studies in Hillslope Hydrology. John Wiley \& Sons. Chapter 11, pp. 365-400.

Askew, A.J., 1970. Variation in lag time for natural catchments. J. Hydraul. Div., ASCE, 96 (HY2): $317-$ 330 .

Bathurst, J.C., 1986. Physically-based distributed modeling of an upland catchment using the Systeme Hydrologique Europeen. J. Hydrol., 87: 79-102.

Beven, K., 1984. Infiltration into a class of vertically non-uniform soils. Hydrol. Sci. J., 29(4): 425-434.

Beven, K., 1989. Changing ideas in hydrology — the case of physically-based models. J. Hydrol., 105: 157 172.

Beven, K.J. and Kirkby, M.J., 1979. A physically-based, variable contributing area model of basin hydrology. Hydrol. Sci. Bull., 24(1): 43-69.

Brooks, R.H. and Corey, A.T., 1964. Hydraulic properties of porous media. Hydrology Pap. 3, Colorado State University, Fort Collins, CO.

Busoni, E., Calzolari, C. and Torri, D., 1986. Utilizzazione della cartografia pedologica per la stima delle caratteristiche idrologiche del suolo. Gruppo Nazionale per la difesa dalle catastrofi idrogeologiche Consiglio Nationale delle Ricerche Rapporto '86, Genova, pp. 1-9.

Cabral, M.C., Bras, R.L., Tarboton, D. and Entekhabi, D., 1990. A distributed, physically-based, rainfallrunoff model incorporating topography for real-time flood forecasting. Ralph M. Parsons Lab. Rep. N. 332, MIT Department of Civil Engineering, Cambridge, MA. 
Cabral, M.C., Garrote, L., Bras, R.L. and Entekhabi, D., 1992. Kinematic infiltration in vertically heterogeneous, anisotropic and sloped soils. Adv. Water Resour., 15: 311-324.

Carlà, R., Carrara, A. and Federici, G., 1987. Generazione di modelli digitali dei terreno ad alta precisione. Publ. No. 0/87, Dip. Ing. Civile, Univ. di Firenze.

Duckstein, L., Ambrus, S. and Davis, D.R., 1985. Management forecasting requirements. In: M.G. Anderson and T.P. Burt (Editors), Hydrological Forecasting. John Wiley and Sons, Chapter 16, pp. 559-586.

Dunne, T. and Black, R.D., 1970. Partial area contributions to storm runoff in a small New England watershed. Water Resour. Res., 6(5): 1296-1311.

Garrote, L. and Bras, R.L., 1993. Real-time modeling of river basin response using radar-generated rainfall maps and a distributed hydrologic database. Ralph M. Parsons Lab. Rep. N. 337, MIT Department of Civil Engineering, Cambridge, MA.

Garrote, L. and Bras, R.L., 1995. An integrated software environment for real-time use of a distributed hydrologic model. J. Hydrol., 167: 307-326.

Hornberger, G.M., Beven, K.J., Cosby, B.J. and Sappington, D.E., 1985. Shenandoah Watershed study: Calibration of a topography-based, variable contributing area hydrological model to a small watershed. Water Resour. Res., 21(12): 1841-1850.

Kellerhalls, R., 1970. Runoff routing through steep natural channels. J. Hydraul. Div., ASCE, 96(HY11): 2201-2217.

Mein, R.G., Laurenson, E.M. and McMahon, T.A., 1974. Simple nonlinear model for flood estimation. J. Hydraul. Div., ASCE, 100(HY11): 1057-1518.

O'Loughlin, E.M., 1981. Saturation regions in catchments and their relations to soil and topographic properties. J. Hydrol., 53: 229-246.

Pilgrim, D.H., 1977. Isochrones of travel time and distribution of flood storage from a tracer study on a small watershed. Water Resour. Res., 13(3): 587-595.

Rogers, C.C.M., Beven, K.J., Morris, E.M. and Anderson, M.G., 1985. Sensitivity analysis, calibration and predictive uncertainty of the institute of hydrology distributed model. J. Hydrol., 81: 179-191.

Tarboton, D., Bras, R.L. and Rodríguez-Iturbe, I., 1991. On the extraction of channel networks from digital elevation data. Hydrol. Process., 5(1): 81-100. 